\title{
Correction to: Electrooxidation of phenol in alcohols and establishment of the permeability of the electrodeposited films
}

\author{
László Kiss $^{1,3} \cdot$ Dóra Bősz $^{1}$. Ferenc Kovács ${ }^{1} \cdot$ Heng Li ${ }^{4,5}$. \\ Sándor Kunsági-Máté ${ }^{1,2,3}$ \\ Published online: 6 February 2019 \\ ๑) Springer-Verlag GmbH Germany, part of Springer Nature 2019
}

\section{Correction to: Polym. Bull. (2019) 76:215-226 https://doi.org/10.1007/s00289-018-2372-4}

In the original publication, first author's affiliation was incorrectly published as 'Department of Pharmaceutical Chemistry, University of Pécs, Rókus Street 2, Pecs 7624, Hungary'. The correct affiliation should read as below.

1. Department of General and Physical Chemistry, University of Pécs, Ifjúság Street 6, Pecs 7624, Hungary

2. János Szentágothai Research Center, Ifjúság Street 20, Pecs 7624, Hungary

Publisher's Note Springer Nature remains neutral with regard to jurisdictional claims in published maps and institutional affiliations.

The original article can be found online at https://doi.org/10.1007/s00289-018-2372-4.

László Kiss

kissl@gamma.ttk.pte.hu

1 Department of General and Physical Chemistry, University of Pécs, Ifjúság Street 6, Pecs 7624, Hungary

2 Department of Pharmaceutical Chemistry, University of Pécs, Rókus Street 2, Pecs 7624, Hungary

3 János Szentágothai Research Center, Ifjúság Street 20, Pecs 7624, Hungary

4 Department of Physics, Fujian Provincial Key Laboratory of Semiconductors and Applications, Collaborative Innovation Center for Optoelectronic Semiconductors and Efficient Devices, Xiamen University, Xiamen 361005, People's Republic of China

5 Jiujiang Research Institute of Xiamen University, Jiujiang 332000, People’s Republic of China 